\title{
Vascular $\mathrm{K}_{\text {ATP }}$ channels mitigate severe muscle $\mathrm{O}_{2}$ delivery- utilization mismatch during contractions in chronic heart failure rats
}

\author{
Clark T. Holdsworth ${ }^{1,}{ }^{,}$, Scott K. Ferguson ${ }^{1}$, Trenton D. Colburn ${ }^{2}$, Alexander J. Fees ${ }^{2}$, Jesse \\ C. Craig ${ }^{2}$, Daniel M. Hirai ${ }^{2}$, David C. Poole ${ }^{1,2}$, and Timothy I. Musch ${ }^{1,2}$ \\ ${ }^{1}$ Department of Anatomy and Physiology, Kansas State University, Manhattan, KS, 66506, USA \\ ${ }^{2}$ Department of Kinesiology, Kansas State University, Manhattan, KS, 66506, USA
}

\begin{abstract}
The vascular ATP-sensitive $\mathrm{K}+\left(\mathrm{K}_{\mathrm{ATP}}\right)$ channel is a mediator of skeletal muscle microvascular oxygenation $\left(\mathrm{PO}_{2} \mathrm{mv}\right)$ during contractions in health. We tested the hypothesis that $\mathrm{K}_{\mathrm{ATP}}$ channel function is preserved in chronic heart failure (CHF) and therefore its inhibition would reduce $\mathrm{PO}_{2} \mathrm{mv}$ and exacerbate the time taken to reach the $\mathrm{PO}_{2} \mathrm{mv}$ steady-state during contractions of the spinotrapezius muscle. Moreover, we hypothesized that subsequent $\mathrm{K}_{\mathrm{ATP}}$ channel activation would oppose the effects of this inhibition. Muscle $\mathrm{PO}_{2} \mathrm{mv}$ (phosphorescence quenching) was measured during $180 \mathrm{~s}$ of $1-\mathrm{Hz}$ twitch contractions ( $\sim 6 \mathrm{~V}$ ) under control, glibenclamide (GLI, $\mathrm{K}_{\text {ATP }}$ channel antagonist; $5 \mathrm{mg} / \mathrm{kg}$ ) and pinacidil (PIN, $\mathrm{K}_{\mathrm{ATP}}$ channel agonist; $5 \mathrm{mg} / \mathrm{kg}$ ) conditions in 16 male Sprague-Dawley rats with CHF induced via myocardial infarction (coronary artery ligation, left ventricular end-diastolic pressure: $18 \pm 1 \mathrm{mmHg}$ ). GLI reduced baseline $\mathrm{PO}_{2} \mathrm{mv}$ (control: $28.3 \pm 0.9$, GLI: $24.8 \pm 1.0 \mathrm{mmHg}, p<0.05$ ), lowered mean $\mathrm{PO}_{2} \mathrm{mv}$ (average $\mathrm{PO}_{2} \mathrm{mv}$ during the overall time taken to reach the steady-state; control: $20.6 \pm 0.6$, GLI: $17.6 \pm 0.3 \mathrm{mmHg}, p<0.05)$, and slowed the attainment of steady-state $\mathrm{PO}_{2} \mathrm{mv}$ (overall mean response time; control: $66.1 \pm 10.2$, GLI: 93.6 \pm 7.8 $\mathrm{s}, p<0.05$ ). PIN opposed these effects on the baseline $\mathrm{PO}_{2} \mathrm{mv}$, mean $\mathrm{PO}_{2} \mathrm{mv}$ and time to reach the steady-state $\mathrm{PO}_{2} \mathrm{mv}$ ( $p<0.05$ for all vs. GLI). Inhibition of $\mathrm{K}_{\text {ATP }}$ channels exacerbates the transient mismatch between muscle $\mathrm{O}_{2}$ delivery and utilization in heart failure rats and this effect is opposed by PIN. These data reveal that the $\mathrm{K}_{\text {ATP }}$ channel constitutes one of the select few wellpreserved mechanisms of skeletal muscle microvascular oxygenation control in CHF.
\end{abstract}

\section{Keywords}

glibenclamide; kinetics; phosphorescence quenching; exercise hyperemia; pinacidil

\footnotetext{
*Corresponding author: Clark T. Holdsworth, Ph.D., 228 Coles Hall, Department of Anatomy and Physiology, College of Veterinary Medicine, Kansas State University, Manhattan, KS 66506-5802, Tel.: 607-743-5805, clark40@k-state.edu.

Publisher's Disclaimer: This is a PDF file of an unedited manuscript that has been accepted for publication. As a service to our customers we are providing this early version of the manuscript. The manuscript will undergo copyediting, typesetting, and review of the resulting proof before it is published in its final citable form. Please note that during the production process errors may be discovered which could affect the content, and all legal disclaimers that apply to the journal pertain.

Conflict disclosures

None.
} 


\section{Introduction}

Oxygen transfer to peripheral tissues via both convective and diffusive transport routes is routinely interrupted as part of the inexorable progression of chronic, congestive heart failure (Hirai et al., 2015; Poole et al., 2012). Decrements in skeletal muscle blood flow and vascular conductance combined with derangement of capillary structure, geometry and hemodynamics lower the muscle microvascular $\mathrm{O}_{2}$ pressure $\left(\mathrm{PO}_{2} \mathrm{mv}\right)$ and impair bloodmyocyte $\mathrm{O}_{2}$ flux thereby reducing work capacity commensurate with the severity of chronic heart failure (CHF) (Miyazaki et al., 2007; Piepoli et al., 2010a, 2010b). Muscle $\mathrm{PO}_{2} \mathrm{mv}$ is a powerful measurement as it represents the final pressure head driving blood-myocyte $\mathrm{O}_{2}$ flux. More importantly, because $\mathrm{PO}_{2} \mathrm{mv}$ is set by the ratio of $\mathrm{O}_{2}$-delivery to $\mathrm{O}_{2}$-utilization, and occurs at the terminal cell-to-cell interface of the $\mathrm{O}_{2}$ transport chain, it is impacted by the collective upstream cardiopulmonary perturbations. This makes the $\mathrm{PO}_{2} \mathrm{mv}$ sensitive to both the spatial and temporal aspects of vascular function and therefore invaluable in revealing the $\mathrm{O}_{2}$ transport depredations of diseases such as CHF (Diederich et al., 2002) as well as the role of vasoactive pathways including nitric oxide (NO) function (Ferreira et al., 2006).

Maintaining adequate muscle $\mathrm{PO}_{2} \mathrm{mv}$ requires tight matching of $\mathrm{O}_{2}$-supply to $\mathrm{O}_{2}$-demand given that even transient mismatch can deplete muscle phosphocreatine stores and exacerbate the accumulation of muscle metabolites associated with fatigue such as ADP, $\mathrm{H}+$, $\mathrm{K}+$ and $\mathrm{P}_{\mathrm{i}}$ (Hogan et al., 1992; Richardson et al., 1995; Wilson et al., 1977). Potassium channels that are sensitive to ATP and ADP $\left(\mathrm{K}_{\mathrm{ATP}}\right)$ constitute a potential coupling between tissue metabolism and vasomotor control (i.e. $\mathrm{O}_{2}$ supply) via $\mathrm{K}^{+}$efflux-induced hyperpolarization. Accordingly, recent studies in isolated skeletal muscle arterioles demonstrate that the $\mathrm{K}_{\mathrm{ATP}}$ channel opener levcromakalim evokes both local and conducted vasodilation (Dora, 2017). $\mathrm{K}_{\mathrm{ATP}}$ channel inhibition in vivo exaggerates baroreflex-mediated vasoconstriction (Keller et al., 2004) whereas its activation attenuates a-adrenergic vasoconstriction (Nakai and Ichihara, 1994; Tateishi and Faber, 1995). However, it remains unclear under which circumstances this channel is obligatory for adequate skeletal muscle $\mathrm{O}_{2}$ transport in health and disease.

Individual studies of $\mathrm{K}_{\mathrm{ATP}}$ channel inhibition are equivocal; some demonstrating robust effects on the magnitude of the hyperemic response to exercise (Banitt et al., 1996; Bank et al., 2000; Bijlstra et al., 1996; Holdsworth et al., 2015) with others finding no change (Duncker et al., 2001; Farouque and Meredith, 2003; Schrage et al., 2006). However, conditions of the local microenvironment are crucial to the role of the channel in vivo and will differ among species, disease states and degree of metabolic stress (e.g. exercise). In particular, $\mathrm{K}_{\mathrm{ATP}}$ channel function is likely to be an essential response to ischemia and the resultant tissue hypoxia (Bijlstra et al., 1996; Nakai and Ichihara, 1994; Suzuki et al., 2002; Tateishi and Faber, 1995; Wheaton and Chandel, 2011). Since these are common attributes of skeletal muscle in CHF patients blocking vascular $\mathrm{K}_{\mathrm{ATP}}$ channel function may exaggerate muscle $\mathrm{O}_{2}$ transport dysfunction in this condition. This is a relevant scenario in patients with diabetes-CHF comorbidities because sulphonylureas, such as glibenclamide (GLI), are widely prescribed for the management of hyperglycemia, and despite apparent high in vitro pancreatic $\mathrm{K}_{\mathrm{ATP}}$ channel affinity, their clinical use is associated with cardiovascular 
morbidity and mortality (Fadini et al., 2015; Morgan et al., 2014; Simpson et al., 2006). While the cardiovascular effects of sulphonylureas in diabetic patients are a consideration for prescription guidelines, the direct, peripheral vascular consequences of sulphonylurea use in $\mathrm{CHF}$ are not well described.

The purpose of this study was to test the hypothesis that vascular $\mathrm{K}_{\text {ATP }}$ channel function is preserved in CHF and, therefore, its inhibition via GLI would impair the matching of muscle $\mathrm{O}_{2}$ delivery-to-utilization following the onset of electrically-induced contractions. This would be reflected by lowered $\mathrm{PO}_{2} \mathrm{mv}$ and slowed kinetics (i.e. increased overall time to reach steady-state) following GLI superfusion of the spinotrapezius muscle of CHF rats. Moreover, we hypothesized that these effects of GLI would be opposed by the $\mathrm{K}_{\mathrm{ATP}}$ channel activator pinacidil (PIN).

\section{Methods}

\subsection{Ethical approval}

All procedures were approved by the Institutional Animal Care and Use Committee of Kansas State University under the guidelines established by the National Institutes of Health. 16 adult male Sprague-Dawley rats (3-6 months old) were maintained in accredited animal facilities (Association for the Assessment and Accreditation of Laboratory Animal Care) at Kansas State University on a 12-h light/12-h dark cycle with food and water provided ad libitum.

\subsection{Myocardial infarction procedures}

All rats underwent induction of a myocardial infarction (MI) via ligation of the left main coronary artery which has been shown to result reliably in the development of moderate to severe CHF (Musch and Terrell, 1992). Briefly, each rat was anesthetized with a gas mixture of 5\% isoflurane- $\mathrm{O}_{2}$ and intubated for mechanical ventilation on a rodent respirator (model 680, Harvard Instruments, Holliston, USA) with subsequent maintenance on a 3\% isoflurane- $\mathrm{O}_{2}$ gas mixture for the duration of the procedure. A left thoracotomy was performed to expose the heart through the fifth intercostal space. Exteriorization of the heart provided access to the left main coronary artery which was ligated with a 6-0 silk suture $\sim 1-2 \mathrm{~mm}$ distal to the edge of the left atrium. The muscles of the thorax were then closed with 4-0 gut, and the skin incision was closed with 3-0 silk followed by an administration of the analgesic agents bupivacaine $(1.5 \mathrm{mg} / \mathrm{kg}$ subcutaneously) and buprenorphine $(0.01-0.05$ $\mathrm{mg} / \mathrm{kg}$ i.m.) as well as ampicillin $(50 \mathrm{mg} / \mathrm{kg}$ i.m.) to reduce the risk of infection. Upon removal from mechanical ventilation and withdrawal of anesthesia the rats were monitored $\sim 8-12 \mathrm{~h}$ post-operatively for the development of arrhythmias and undue stress with care administered as needed. The recovery duration prior to the final, $\mathrm{PO}_{2} \mathrm{mv}$ protocol was $\geq 21$ days which is consistent with the time course for complete remodeling of necrotic myocardial tissue (Fishbein et al., 1978). During this time the rats were monitored daily (appetite, weight loss, gait/posture, etc.) in conjunction with the university veterinary staff. 


\subsection{Surgical instrumentation}

On the day of the final protocol the rats were anesthetized initially with a 5\% isoflurane- $\mathrm{O}_{2}$ mixture and maintained on a $3 \%$ isoflurane- $\mathrm{O}_{2}$ mixture for the duration of the surgical instrumentation. The carotid artery was cannulated and a two-French-catheter-tipped pressure transducer (Millar Instruments, Houston, USA) was advanced into the left ventricle (LV) for the measurement of LV end diastolic pressure (LVEDP). Subsequently, cannulation of both the carotid and caudal arteries was performed with PE-10 connected to PE-50 (IntraMedic polyethylene tubing, Clay Adams, Spark, USA) for the measurement of mean arterial pressure (MAP) and heart rate (HR) as well as infusion of the phosphorescent probe Oxyphor G2 (Oxygen Enterprises, Philadelphia, PA, USA; carotid) and for blood sampling and administration of anesthetics (caudal). Isoflurane- $\mathrm{O}_{2}$ inhalation was progressively removed as anesthesia was maintained with pentobarbital sodium administered via the caudal artery catheter to effect. Depth of anesthesia was monitored at frequent and regular intervals via the blink and toe-pinch reflexes as well as magnitude and frequency of ventilation. Access to the spinotrapezius was achieved by surgically reflecting the overlying skin and fascia. The spinotrapezius muscle was selected because the fiber-type composition and oxidative capacity closely resemble that of the human quadriceps muscle group which makes it a useful analog of human locomotor muscle (Delp and Duan, 1996). During both the surgical preparation and experimental protocol the muscle was superfused frequently with Krebs-Henseleit bicarbonate-buffered solution consisting of (in $\mathrm{mM}$ ) $4.7 \mathrm{KCl}, 2.0$ $\mathrm{CaCl}_{2}, 2.4 \mathrm{MgSO} 4,131 \mathrm{NaCl}$, and $22 \mathrm{NaHCO} 3$ equilibrated with $5 \% \mathrm{CO}_{2}$ and $95 \% \mathrm{~N}_{2}(\mathrm{pH}$ $7.4,37-38^{\circ} \mathrm{C}$ ). Exposed tissue surrounding the spinotrapezius muscle was covered with Saran wrap (Dow Brands, Indianapolis, IN) to reduce dehydration and confine the exposure of GLI and PIN to the spinotrapezius muscle. Platinum iridium electrodes were sutured to the rostral (cathode) and caudal (anode) regions of the spinotrapezius muscle for electricallyinduced twitch contractions. As previously reported by our laboratory these surgical procedures do not impact the microvascular integrity and responsiveness of the rat spinotrapezius muscle (Bailey et al., 2000).

\subsection{Drugs}

The pharmacological sulphonylurea derivative GLI (494 g/mol; 5-chloro- $N$-(4-[N(cyclohexylcarbamoyl)sulfamoyl]phenethyl)-2-methoxybenzamide; Sigma-Aldrich, St Louis, MO, USA) was used to inhibit vascular $\mathrm{K}_{\mathrm{ATP}}$ channels. Given that GLI is difficult to maintain in solution, $25 \mathrm{mg}$ of GLI was dissolved in 99:1 ratio of distilled water/ $\mathrm{NaOH}$ (1 M) during continuous sonication to produce a $2.5 \mathrm{mg} / \mathrm{ml}$ stock solution. A $5 \mathrm{mg} / \mathrm{kg}$ dose was drawn from the stock solution and diluted to $\sim 3 \mathrm{ml}$ with Krebs-Henseleit solution. PIN (245 g/mol; N-cyano-N'-pyridin-4-yl-N"-(1,2,2-trimethylpropyl)guanidine; Sigma-Aldrich, St Louis, MO, USA) is readily dissolved in distilled water and was diluted to $\sim 3 \mathrm{ml}$ with Krebs-Henseleit solution before being administered to oppose vascular $\mathrm{K}_{\mathrm{ATP}}$ channel inhibition at the same dose as GLI.

\subsection{Experimental protocol}

Three separate contraction bouts were performed under control (vehicle), GLI ( $5 \mathrm{mg} / \mathrm{kg}$ ) and PIN $(5 \mathrm{mg} / \mathrm{kg}$ ) conditions. Drug doses and experimental protocol were selected based on 
previous investigations examining the functional role of $\mathrm{K}_{\mathrm{ATP}}$ channels on skeletal muscle blood flow and $\mathrm{PO}_{2} \mathrm{mv}$ (Holdsworth et al., 2016, 2015) and preliminary studies in our laboratory. The vehicle was administered for control via superfusion $(3 \mathrm{ml})$ of the spinotrapezius during $180 \mathrm{~s}$ of continuous $\mathrm{PO}_{2} \mathrm{mv}$ recording. The recording was extended for an additional 90-180 s to ensure that baseline $\mathrm{PO}_{2} \mathrm{mv}$ had stabilized at which time muscle contraction was evoked via electrical stimulation $(1 \mathrm{~Hz}, \sim 6 \mathrm{~V}, 2-\mathrm{ms}$ pulse duration, model s48; Grass Technologies, Quincy, MA) for $180 \mathrm{~s}$. This protocol has been shown to increase spinotrapezius muscle blood flow four-to five-fold and metabolic rate six- to sevenfold without altering blood $\mathrm{pH}$ and is consistent with moderate intensity exercise (Behnke et al., 2002; Hirai et al., 2013). Immediately upon cessation of electrical stimulation an arterial blood sample was drawn $(\sim 0.8 \mathrm{ml})$ for the determination of blood gases, hematocrit, $\mathrm{pH}$, [lactate] and [glucose]. This was followed by a brief washout with Krebs-Henseleit solution and a 20-30 min recovery period, after which the second contraction bout was performed in an identical fashion to the first after the superfusion of GLI (5 mg/kg). This was repeated for the third contraction bout with the administration of PIN. As previously reported by our laboratory, >20 min recovery elicits reproducible $\mathrm{PO}_{2} \mathrm{mv}$ responses (Copp et al., 2009; Herspring et al., 2008). Given the long-lasting effects of GLI and the possibility that this drug may not washout completely with Krebs-Henseleit superfusion and the recovery period employed herein (Thomas et al., 1997; cf. Brayden, 2002), PIN was compared to GLI only as described in the Statistical analysis section below. At the end of the protocol, rats were euthanized with intra-arterial pentobarbital sodium overdose $(>50 \mathrm{mg} / \mathrm{kg})$ and subsequent removal of the heart. The lungs, right ventricle (RV), LV and atria were removed and weighed. Measurement of infarct size in the LV was made via planimetry as described previously (Ferreira et al., 2006).

\subsection{Spinotrapezius $\mathrm{PO}_{2} \mathrm{mv}$ measurement}

$\mathrm{PO}_{2} \mathrm{mv}$ was measured via phosphorescence quenching using a frequency domain phosphorometer (PMOD 5000; Oxygen Enterprises, Philadelphia, PA). As described previously (Behnke et al., 2001), this technique applies the Stern-Volmer relationship (Rumsey et al., 1988), which describes the quantitative $\mathrm{O}_{2}$ dependence of the phosphorescent probe $\mathrm{G} 2$ via the equation:

$$
\mathrm{PO}_{2} \mathrm{mv}=\left[\left(\tau^{\circ} / \tau\right)-1\right] /\left(\mathrm{k}_{\mathrm{Q}} \cdot \tau^{\circ}\right)
$$

where $\mathrm{k}_{\mathrm{Q}}$ is the quenching constant and $\tau$ and $\tau^{\circ}$ are the phosphorescence lifetimes at the ambient $\mathrm{O}_{2}$ concentration and in the absence of $\mathrm{O}_{2}$, respectively. For the phosphorescent probe $\mathrm{G} 2, \mathrm{k}_{\mathrm{Q}}$ is $273 \mathrm{mmHg}^{-1} \mathrm{~s}^{-1}$ and $\tau^{\circ}$ is $251 \mu$ s (Bodmer et al., 2012; Dunphy et al., 2002). These characteristics do not change over the physiological range of $\mathrm{pH}(\sim 7.4)$ and temperature $\left(\sim 38^{\circ} \mathrm{C}\right)$ in vivo and, therefore, the phosphorescence lifetime is affected solely by the $\mathrm{O}_{2}$ partial pressure. The Pd-porphyrin cores of phosphor probes bind to albumin; the primary macromolecule in plasma. This quality as well as the probe's negative charge ensure restriction to the vascular compartment, of which, the capillary bed volumetrically constitutes the major intramuscular space (Poole et al., 2004). After infusion of G2 the common end of the bifurcated light guide with a $>500 \mu \mathrm{m}$ penetration depth was positioned 
2-4 mm superficial to the dorsal surface of the exposed spinotrapezius muscle in an area devoid of macro-vessels. The phosphorometer modulates sinusoidal excitation frequencies between $100 \mathrm{~Hz}$ and $20 \mathrm{kHz}$ and allows phosphorescence lifetime measurements from $10 \mu \mathrm{s}$ to $\sim 2.5 \mathrm{~ms}$. $\mathrm{PO}_{2} \mathrm{mv}$ was measured continuously and recorded at 2-s intervals throughout the duration of the experimental protocol.

\subsection{Analysis of spinotrapezius $\mathrm{PO}_{2} \mathrm{mv}$ kinetics}

$\mathrm{PO}_{2} \mathrm{mv}$ time course was determined via exponential regression analysis by applying the Levenberg-Marquardt algorithm (SigmaPlot 11.0; Systat software, San Jose, CA) to the contraction-induced $\mathrm{PO}_{2} \mathrm{mv}$ transient. $\mathrm{PO}_{2} \mathrm{mv}$ responses were fit with either a one- or twocomponent model as follows.

One component:

$$
\mathrm{PO}_{2 \mathrm{mv}(t)}=\mathrm{PO}_{2 \mathrm{mv}(\mathrm{BL})}-\Delta_{1} \mathrm{PO}_{2 \mathrm{mv}} \quad\left[1-\mathrm{e}^{-\left(t-\mathrm{TD}_{1} / \tau_{1}\right)}\right]
$$

Two component:

$\mathrm{PO}_{2 \mathrm{mv}(t)}=\mathrm{PO}_{2 \mathrm{mv}(\mathrm{BL})}-\Delta_{1} \quad \mathrm{PO}_{2 \mathrm{mv}} \quad\left[1-e^{-\left(t-\mathrm{TD}_{1} / \tau_{1}\right)}\right]+\Delta_{2} \mathrm{PO}_{2 \mathrm{mv}} \quad\left[1-\mathrm{e}^{-\left(t-\mathrm{TD}_{2} / \tau_{2}\right)}\right]$

$\mathrm{PO}_{2} \mathrm{mv}_{(t)}$ is the $\mathrm{PO}_{2} \mathrm{mv}$ at a given time $t, \mathrm{PO}_{2} \mathrm{mv}_{(\mathrm{BL})}$ corresponds to the pre-contracting resting $\mathrm{PO}_{2} \mathrm{mv} ; \Delta_{1}$ and $\Delta_{2}$ are the amplitudes for the first and second components, respectively; $\mathrm{TD}_{1}$ and $\mathrm{TD}_{2}$ are the independent time delays for each component; and $\tau_{1}$ and $\tau_{2}$ are the time constants (i.e. time to $63 \%$ of the response) for each component. Goodness of fit was determined using three criteria: the coefficient of determination, sum of squared residuals, and visual inspection (Behnke et al., 2002).

The mean response time (MRT $)$ was used to describe the overall dynamics of the $\mathrm{PO}_{2} \mathrm{mv}$ fall following the onset of muscle contractions via the equation:

$$
\mathrm{MRT}_{1}=\mathrm{TD}_{1}+\tau_{1}
$$

The $\mathrm{MRT}_{1}$ analysis was limited to the first component of the $\mathrm{PO}_{2} \mathrm{mv}$ response given that inclusion of an emergent second component underestimates the speed of the $\mathrm{PO}_{2} \mathrm{mv}$ fall at the onset of contractions. In the event of a second component the $\mathrm{MRT}_{2}$ was calculated using the following equation:

$$
\mathrm{MRT}_{2}=\mathrm{TD}_{2}+\tau_{2}
$$

To determine the overall time taken to reach the steady-state $\mathrm{PO}_{2} \mathrm{mv}$ the $\mathrm{MRT}_{\text {Total }}$ was calculated via the equation:

$$
\mathrm{MRT}_{\text {Total }}=\mathrm{MRT}_{1}+\mathrm{MRT}_{2}
$$


The $\mathrm{MRT}_{\text {Total }}$ does not equal the sum of the average $\mathrm{MRT}_{1}$ and $\mathrm{MRT}_{2}$ because the calculation of $\mathrm{MRT}_{\mathrm{Total}}$ is independent of the average of $\mathrm{MRT}_{2}$. The purpose of the second component kinetics parameters is to represent the speed with which the $\mathrm{PO}_{2} \mathrm{mv}_{(\mathrm{SS})}$ is reached after the initial fall in $\mathrm{PO}_{2} \mathrm{mv}$. For this reason, the $\mathrm{MRT}_{2}$ averages are calculated from rats with a two-component fit only. However, the calculation of $\mathrm{MRT}_{\text {Total }}$ necessarily reflects the absence of $\mathrm{MRT}_{2}$ (i.e. entries of zero) for rats fit with a one-component model.

Mean $\mathrm{PO}_{2} \mathrm{mv}$ was calculated as the average $\mathrm{PO}_{2} \mathrm{mv}$ from the contractions onset through the duration of $\mathrm{MRT}_{\text {Total }}$.

\subsection{Statistical analysis}

MAP and HR were compared between conditions and across time points via 2-way repeated measures ANOVA with Student Newman Keuls post-hoc tests as necessary. Kinetics parameters were compared between conditions with 1-way, repeated measures ANOVA on the basis of the a priori hypotheses. Student Newman Keuls post-hoc tests were used to compared control/GLI and GLI/PIN when necessary. Results are presented as means $\pm \mathrm{SE}$. The level of significance was set at $p<0.05$.

\section{Results}

The final body weight for all CHF rats was $463 \pm 12 \mathrm{~g}$. Table 1 summarizes the descriptive statistics for the central indices of CHF. Arterial blood [lactate], [glucose], $\mathrm{PO}_{2}, \mathrm{PCO}_{2}, \mathrm{O}_{2}$ saturation, hematocrit and $\mathrm{pH}$ were not different with GLI relative to control and were also not different after PIN superfusion compared to GLI ( $p>0.05$ for all; data not shown). The MAP (control: $110 \pm 4$, GLI: $114 \pm 5 \mathrm{mmHg}$ ) and HR (control: $326 \pm 10$, GLI: $337 \pm 14$ beats $/ \mathrm{min}$ ) at the start of contractions with GLI were not different from control ( $p>0.05$ for both). PIN reduced MAP at the start of contractions compared to GLI (PIN: $100 \pm 6$, GLI: $114 \pm 5 \mathrm{mmHg}, p<0.05$ ), but did not change HR (PIN: $367 \pm 14$, GLI: $337 \pm 14$ beats/min, $p>0.05)$.

Muscle $\mathrm{PO}_{2} \mathrm{mv}$ responses from rest to contractions are shown in Fig. 1 and the kinetics parameters are provided in Table 2 . The goodness of fit for the models was demonstrated by an $\mathrm{r}^{2}$ of $0.97 \pm 0.01$ and the sum of squared residuals of $18.9 \pm 3.0$. Overall, the mean $\mathrm{PO}_{2} \mathrm{mv}$ over the early contractions transient was significantly reduced with GLI relative to control (control: $20.6 \pm 0.6$, GLI: $17.6 \pm 0.3 \mathrm{mmHg}, p<0.05$ ). During the control condition 11 of 16 rats exhibited $\mathrm{PO}_{2}$ mv profiles that transiently fell below the contracting steady-state (termed an "undershoot", $\Delta_{2} \mathrm{PO}_{2} \mathrm{mv}$ ) necessitating a two-component model fit. Conversely, during GLI the two-component model was required for 15 of 16 rats and during PIN for 5 of 12 rats. Compared to control, GLI reduced the $\mathrm{PO}_{2} \mathrm{mv}$ baseline $\left(\mathrm{PO}_{2} \mathrm{mv}(\mathrm{BL})\right)$ prior to contractions. In addition, GLI increased the amplitude of $\Delta_{2} \mathrm{PO}_{2} \mathrm{mv}$ and slowed the attainment of the steady-state as indicated by an increase in the total mean response time $\left(\mathrm{MRT}_{\text {Total }}\right)$.

PIN increased the mean $\mathrm{PO}_{2} \mathrm{mv}$ across $\mathrm{MRT}_{\text {Total }}$ compared to GLI (GLI: $17.6 \pm 0.3$, PIN: $25.7 \pm 0.5 \mathrm{mmHg}, p<0.05$ ). This is in direct opposition to the effect of GLI during the early contraction transient relative to control. PIN also increased both the baseline and steady- 
state $\mathrm{PO}_{2} \mathrm{mv}$ with no difference in $\Delta_{1} \mathrm{PO}_{2} \mathrm{mv}$ relative to the GLI condition. The effects of PIN were such that a faster attainment of the steady-state (i.e. lower $\mathrm{MRT}_{\text {Total }}$ ) was observed when compared to GLI.

\section{Discussion}

$\mathrm{K}_{\mathrm{ATP}}$ channel inhibition via GLI fundamentally altered the spinotrapezius $\mathrm{PO}_{2} \mathrm{mv}$ profile such that mean $\mathrm{PO}_{2} \mathrm{mv}$ was lowered at rest and following the onset of contractions in CHF rats. The major effects of GLI were 1) a reduction in the baseline $\mathrm{PO}_{2} \mathrm{mv}$; 2) a near doubling of the $\mathrm{PO}_{2} \mathrm{mv}$ undershoot amplitude with a $42 \%$ increase in the overall time to reach the contracting steady-state and $\mathrm{MRT}_{\text {Total }}$; and 3) a reduced mean $\mathrm{PO}_{2} \mathrm{mv}$ during the transition from contraction onset to the steady-state $\mathrm{PO}_{2} \mathrm{mv}$. These data indicate that vascular smooth muscle and/or endothelial $\mathrm{K}_{\mathrm{ATP}}$ channel function are essential to the control of muscle $\mathrm{PO}_{2} \mathrm{mv}$ kinetics at the onset of contractions in CHF, and the $\mathrm{K}_{\mathrm{ATP}}$ channel may represent one of the select few well-preserved mechanisms of skeletal muscle vascular control in CHF. This $\mathrm{K}_{\text {ATP }}$ channel-conferred protection against severe $\mathrm{O}_{2}$-delivery to $\mathrm{O}_{2}$-utilization mismatch during contractions should raise serious concerns when sulphonylureas such as GLI are prescribed for patients with coincident diabetes and CHF.

The central indices of dysfunction (Table 1) support that moderate CHF was induced in these animals (Ferreira et al., 2006) which is consistent with New York Heart Association (NYHA) class II and III CHF in humans (Musch et al., 1988). The spectrum included animals with elevated LVEDP's (up to $27 \mathrm{mmHg}$ ) and MI size's greater than $40 \%$ (severe $\mathrm{CHF}$ ) however the sample size was not sufficient for adequately powered statistical comparisons between moderate and severe sub-groups. Thus, the moderate CHF herein may underestimate the effect of GLI on the $\mathrm{PO}_{2} \mathrm{mv}$ profiles during contractions. Nonetheless, moderate CHF induced via the rat model of coronary artery ligation does result in decrements to skeletal muscle blood flow, vascular conductance, $\mathrm{PO}_{2}$ mv kinetics, $\dot{\mathrm{V}} \mathrm{O}_{2}$ max, and time-to-exhaustion during exercise akin to NYHA Class II and III CHF in humans (Hirai et al., 2015; Musch and Terrell, 1992; Poole et al., 2012; Richardson et al., 2003).

$\mathrm{K}_{\text {ATP }}$ channel manipulation of the steady-state $\mathrm{O}_{2}$ delivery has been characterized previously for in vivo electrical stimulation (Thomas et al., 1997), reactive hyperemia (Banitt et al., 1996; Bank et al., 2000; Bijlstra et al., 1996) and exercise-induced hyperemia (Holdsworth et al., 2015). Our laboratory has also demonstrated that GLI increased the prevalence of the undershoot and prolonged the time to reach the contracting steady-state $\mathrm{PO}_{2} \mathrm{mv}$ in the spinotrapezius muscle of healthy rats (Holdsworth et al., 2016). The available evidence is equivocal in regards to $\dot{\mathrm{V}} \mathrm{O}_{2}$ and mitochondrial respiration with modulation of $\mathrm{K}_{\text {ATP }}$ channel function. Some investigations indicate no appreciable change in $\dot{\mathrm{V}} \mathrm{O}_{2}$ during whole body exercise with GLI in diabetic patients (Larsen et al., 1999) and that mitochondrial $\mathrm{K}_{\mathrm{ATP}}$ channel inhibition does not impact the $\mathrm{O}_{2}$ cost of myocardial contractions (Chen et al., 2001). Other groups have found that GLI reduces diaphragmatic $\dot{\mathrm{V}} \mathrm{O}_{2}$ in canines (largely driven by reductions in $\mathrm{O}_{2}$ delivery) (Vanelli et al., 1994) and that skeletal muscle mitochondrial respiration is impaired by small doses of GLI (Montoya-Pérez et al., 2010). While GLI-induced changes in $\mathrm{O}_{2}$ delivery may constitute the primary driver for the 
perturbed $\mathrm{PO}_{2} \mathrm{mv}$ profile, it is not possible to identify whether the superfusion method utilized herein affected $\mathrm{K}_{\mathrm{ATP}}$ channels present specifically within the arteriole wall and/or myocyte (Flagg et al., 2010; Jackson, 2000). Further studies in CHF are required to establish whether manipulation of $\mathrm{K}_{\mathrm{ATP}}$ channel function could be influenced by the mode of drug delivery and/or specific tissue of interest.

The small-muscle mass preparation used herein poses an advantage for investigations of peripheral vascular control because it does not tax the limits of cardiac output. This is a strength for investigations of vascular $\mathrm{K}_{\mathrm{ATP}}$ channels in CHF because the channel's role in cardiac function may obfuscate detection and/or interpretation of the impact on peripheral vascular control (Nichols et al., 1991; Noma, 1983). Although no direct assessment of $\mathrm{K}_{\text {ATP }}$ channel activity and/or expression was performed in the current study, in CHF rats it appears that the vascular $\mathrm{K}_{\mathrm{ATP}}$ channel pathway remains functional given the marked sensitivity of the $\mathrm{PO}_{2} \mathrm{mv}$ profile to both GLI and PIN. The $\mathrm{PO}_{2} \mathrm{mv}$ profiles of the CHF rats herein exhibit the characteristic undershoot demonstrated previously by our laboratory (Behnke et al., 2001; Hirai et al., 2014) and permitted the statistical comparison of the second kinetics component (i.e. undershoot) between control and GLI which was not possible in our previous investigation of $\mathrm{K}_{\mathrm{ATP}}$ function in healthy rats (Holdsworth et al., 2016). Specifically, the present investigation revealed that GLI elevated the magnitude of the $\mathrm{PO}_{2} \mathrm{mv}$ undershoot and slowed the overall time taken to reach steady-state. In contrast to previous results in healthy rats (Holdsworth et al., 2016), baseline $\mathrm{PO}_{2} \mathrm{mv}$ was reduced with

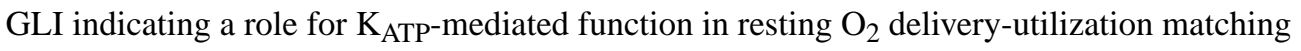
in CHF. In addition, our findings indicate that PIN opposed the major effects promoted by GLI on muscle $\mathrm{PO}_{2} \mathrm{mv}$ thus indicating modulation of $\mathrm{K}_{\mathrm{ATP}}$ channel function rather than some non-specific effect with the present experimental protocol.

Intrinsic impairments in specific vasodilatory mechanisms in CHF skeletal muscle such as reduced NO bioavailability (Ferreira et al., 2006) will place greater reliance on $\mathrm{K}_{\text {ATP }}$ channel function during contractions. Figure 2 demonstrates different responses to GLI on the spinotrapezius muscle $\mathrm{PO}_{2} \mathrm{mv}$ in healthy (data from Holdsworth et al., 2016) versus the present investigation with CHF rats. That GLI induced a greater reduction in muscle $\mathrm{PO}_{2} \mathrm{mv}$ during the early contraction transient in CHF compared to healthy animals is consistent with augmented reliance of $\mathrm{K}_{\mathrm{ATP}}$ channel function on $\mathrm{O}_{2}$ delivery-utilization matching in this disease. Crucially, greater $\mathrm{O}_{2}$ delivery-utilization mismatch with GLI in CHF occurs concomitantly with the slowing of second component (phase II) $\dot{\mathrm{V}} \mathrm{O}_{2}$ kinetics following the onset of contractions (Behnke et al., 2002). Exacerbating the fall in skeletal muscle $\mathrm{PO}_{2} \mathrm{mv}$ due to a sluggish increase in $\mathrm{O}_{2}$ delivery is also likely to impact cellular metabolism and contribute to the slowing of $\dot{\mathrm{V}} \mathrm{O}_{2}$ kinetics and premature fatigue that is prominent in $\mathrm{CHF}$ patients (Ferreira et al., 2005; Hepple et al., 1999; Wheaton and Chandel, 2011; Wilson et al., 1977).

GLI clearly exaggerates many of the CHF-induced perturbations of skeletal muscle $\mathrm{PO}_{2} \mathrm{mv}$ kinetics including elevating the undershoot amplitude and delaying attainment of the contracting steady-state $\mathrm{PO}_{2} \mathrm{mv}$ (Ferreira et al., 2006). This effect is also well-characterized in other $\mathrm{O}_{2}$ supply-limited conditions such as aging (Behnke et al., 2005) and diabetes (Padilla et al., 2007) which are often coincident conditions for CHF patients. The 
exacerbation of this dysregulation with GLI is clinically relevant given that these populations present with severe exercise intolerance (Piepoli et al., 2010a, 2010b; Sacre et al., 2015) due, in part, to a lowering of the skeletal muscle $\mathrm{PO}_{2} \mathrm{mv}$ pressure head intrinsic to those diseases (Hirai et al., 2015; Poole et al., 2012). Both the magnitude and time course (i.e. concomitant with the rise in $\dot{\mathrm{V}} \mathrm{O}_{2}$ following contractions onset) of the decrements in $\mathrm{PO}_{2} \mathrm{mv}$ suggest that degradation of the intracellular metabolic environment is likely to impair muscle work capacity and/or $\dot{\mathrm{V}}_{2}$ kinetics with GLI.

Impairments in contracting muscle $\mathrm{PO}_{2} \mathrm{mv}$ in CHF have been attributed, in part, to reductions in NO bioavailability (Ferreira et al., 2006) and the results herein suggest that preserved $\mathrm{K}_{\text {ATP }}$ function protects against a more severe mismatch of $\mathrm{O}_{2}$-delivery to $\mathrm{O}_{2^{-}}$utilization in this disease. Taken together, the shared contribution of $\mathrm{NO}$ and $\mathrm{K}_{\mathrm{ATP}}$ channel signaling to muscle $\mathrm{PO}_{2} \mathrm{mv}$ suggests that these pathways are not merely independent, parallel mechanisms, but rather synergistic mediators of skeletal muscle vascular and metabolic control. NO has been shown to cause arterial hyperpolarization, in part, via $\mathrm{K}_{\text {ATP }}$ channel activation (Murphy and Brayden, 1995) which may occur through the cGMP intermediary as demonstrated previously in cardiac myocytes (Chai et al., 2011) and cultured smooth muscle cells (Kubo et al., 1994). Furthermore, as a reactive nitrogen species, NO can cause direct S-nitrosylation of cysteine residues found on the SURx subunit (Kawano et al., 2009; Yoshida et al., 2006). Thus, $\mathrm{K}_{\mathrm{ATP}}$ channel activation via NO is likely mediated through a combination of these two mechanisms. The notion that $\mathrm{K}_{\mathrm{ATP}}$ channels can amplify vasodilatory signaling (Cole et al., 2000; Silva et al., 2008) via modulation of membrane potential deserves further investigation and may be valuable clinically (Akrouh et al., 2009).

Both the results herein and large retrospective studies of the association of sulphonylurea monotherapy with cardiovascular mortality and morbidity are cause for concern in diabetic and CHF patients (Fadini et al., 2015; Morgan et al., 2014; Simpson et al., 2006). Our findings demonstrate the additive effect of GLI on $\mathrm{PO}_{2} \mathrm{mv}$ dysregulation in CHF which has been minimally addressed in the risk assessments of sulphonylurea therapy. That the primary muscle $\dot{\mathrm{V}} \mathrm{O}_{2}$ kinetics are significantly slowed in diabetic patients raises an intriguing question as to whether it is a de facto diabetes- or alternatively sulphonlyurea-induced dysfunction of the $\mathrm{K}_{\text {ATP }}$ channel that drives the $\dot{\mathrm{V}} \mathrm{O}_{2}$ kinetics limitation (Bauer et al., 2007; O'Connor et al., 2015; Regensteiner et al., 1998). Clearly, when CHF attenuates other pathways vascular $\mathrm{K}_{\mathrm{ATP}}$ channels remain one of the few potential defenses protecting against a more severe mismatch of $\mathrm{O}_{2}$-delivery to $\mathrm{O}_{2}$-utilization during muscle contractions. The administration of sulphonylureas may pose a previously unrecognized danger in patients afflicted with both $\mathrm{CHF}$ and diabetes where an additional drag on $\mathrm{O}_{2}$ delivery could severely compromise exercise tolerance. The findings herein extend previous investigations of GLI in healthy rats (Holdsworth et al., 2016) by demonstrating a robust perturbation of the $\mathrm{PO}_{2} \mathrm{mv}$ profile at the onset of electrically-induced contractions of the spinotrapezius muscle in CHF rats. The apparent sensitivity of the vascular $\mathrm{K}_{\mathrm{ATP}}$ channels to pharmacologic intervention suggests that, in contrast to the well-established disruption of other mechanisms of vascular control in CHF such as NO synthase uncoupling (Maier et al., 2000; Sindler et al., 2009) and autonomic imbalance (Coats et al., 1994; Wang et al., 2010), preserved vascular $\mathrm{K}_{\text {ATP }}$ 
channel function protects against exaggerated transient skeletal muscle hypoxia during contractions.

\section{Acknowledgements}

We thank K. Sue Hageman for expert technical assistance. These experiments were funded, in part, by Kansas State University SMILE grant awarded to T.I.M. and NIH (HL-1-108328 and HL-2-108328) awarded to D.C.P.

\section{References}

Akrouh A, Halcomb SE, Nichols CG, Sala-Rabanal M. Molecular biology of K(ATP) channels and implications for health and disease. IUBMB Life. 2009; 61:971-978. doi:10.1002/iub.246. [PubMed: 19787700]

Bailey JK, Kindig CA, Behnke BJ, Musch TI, Schmid-Schoenbein GW, Poole DC. Spinotrapezius muscle microcirculatory function: effects of surgical exteriorization. Am. J. Physiol. Heart Circ. Physiol. 2000; 279:H3131-3137. [PubMed: 11087272]

Banitt PF, Smits P, Williams SB, Ganz P, Creager MA. Activation of ATP-sensitive potassium channels contributes to reactive hyperemia in humans. Am. J. Physiol. 1996; 271:H1594-1598. [PubMed: 8897956]

Bank AJ, Sih R, Mullen K, Osayamwen M, Lee PC. Vascular ATP-dependent potassium channels, nitric oxide, and human forearm reactive hyperemia. Cardiovasc. Drugs Ther. 2000; 14:23-29. [PubMed: 10755197]

Bauer TA, Reusch JEB, Levi M, Regensteiner JG. Skeletal muscle deoxygenation after the onset of moderate exercise suggests slowed microvascular blood flow kinetics in type 2 diabetes. Diabetes Care. 2007; 30:2880-2885. doi:10.2337/dc07-0843. [PubMed: 17675540]

Behnke BJ, Barstow TJ, Kindig CA, McDonough P, Musch TI, Poole DC. Dynamics of oxygen uptake following exercise onset in rat skeletal muscle. Respir. Physiol. Neurobiol. 2002; 133:229-239. [PubMed: 12425970]

Behnke BJ, Delp MD, Dougherty PJ, Musch TI, Poole DC. Effects of aging on microvascular oxygen pressures in rat skeletal muscle. Respir. Physiol. Neurobiol. 2005; 146:259-268. doi:10.1016/j.resp. 2004.12.009. [PubMed: 15766914]

Behnke BJ, Kindig CA, Musch TI, Koga S, Poole DC. Dynamics of microvascular oxygen pressure across the rest-exercise transition in rat skeletal muscle. Respir. Physiol. 2001; 126:53-63. [PubMed: 11311310]

Bijlstra PJ, den Arend JA, Lutterman JA, Russel FG, Thien T, Smits P. Blockade of vascular ATPsensitive potassium channels reduces the vasodilator response to ischaemia in humans. Diabetologia. 1996; 39:1562-1568. [PubMed: 8960843]

Bodmer SIA, Balestra GM, Harms FA, Johannes T, Raat NJH, Stolker RJ, Mik EG. Microvascular and mitochondrial $\mathrm{PO}_{2}$ simultaneously measured by oxygen-dependent delayed luminescence. J. Biophotonics. 2012; 5:140-151. doi:10.1002/jbio.201100082. [PubMed: 22114031]

Brayden JE. Functional roles of KATP channels in vascular smooth muscle. Clin. Exp. Pharmacol. Physiol. 2002; 29:312-316. [PubMed: 11985542]

Chai Y, Zhang D-M, Lin Y-F. Activation of cGMP-dependent protein kinase stimulates cardiac ATPsensitive potassium channels via a ROS/calmodulin/CaMKII signaling cascade. PloS One. 2011; 6:e18191. doi:10.1371/journal.pone.0018191. [PubMed: 21479273]

Chen Y, Traverse JH, Zhang J, Bache RJ. Selective blockade of mitochondrial K(ATP) channels does not impair myocardial oxygen consumption. Am. J. Physiol. Heart Circ. Physiol. 2001; 281:H738744. [PubMed: 11454578]

Coats AJ, Clark AL, Piepoli M, Volterrani M, Poole-Wilson PA. Symptoms and quality of life in heart failure: the muscle hypothesis. Br. Heart J. 1994; 72:S36-39. [PubMed: 7946756]

Cole WC, Malcolm T, Walsh MP, Light PE. Inhibition by protein kinase C of the K(NDP) subtype of vascular smooth muscle ATP-sensitive potassium channel. Circ. Res. 2000; 87:112-117. [PubMed: 10903994] 
Copp SW, Ferreira LF, Herspring KF, Hirai DM, Snyder BS, Poole DC, Musch TI. The effects of antioxidants on microvascular oxygenation and blood flow in skeletal muscle of young rats. Exp. Physiol. 2009; 94:961-971. doi:10.1113/expphysiol.2009.048223. [PubMed: 19502293]

Delp MD, Duan C. Composition and size of type I, IIA, IID/X, and IIB fibers and citrate synthase activity of rat muscle. J. Appl. Physiol. 1996; 80:261-270. [PubMed: 8847313]

Diederich ER, Behnke BJ, McDonough P, Kindig CA, Barstow TJ, Poole DC, Musch TI. Dynamics of microvascular oxygen partial pressure in contracting skeletal muscle of rats with chronic heart failure. Cardiovasc. Res. 2002; 56:479-486. [PubMed: 12445889]

Dora KA. Conducted dilatation to ATP and $\mathrm{K}(+)$ in rat skeletal muscle arterioles. Acta Physiol. Oxf. Engl. 2017; 219:202-218. doi:10.1111/apha.12656.

Duncker DJ, Oei HH, Hu F, Stubenitsky R, Verdouw PD. Role of K(ATP)(+) channels in regulation of systemic, pulmonary, and coronary vasomotor tone in exercising swine. Am. J. Physiol. Heart Circ. Physiol. 2001; 280:H22-33. [PubMed: 11123214]

Dunphy I, Vinogradov SA, Wilson DF. Oxyphor R2 and G2: phosphors for measuring oxygen by oxygen-dependent quenching of phosphorescence. Anal. Biochem. 2002; 310:191-198. [PubMed: 12423638]

Fadini GP, Avogaro A, Degli Esposti L, Russo P, Saragoni S, Buda S, Rosano G, Pecorelli S, Pani L, OsMed Health-DB Network. Risk of hospitalization for heart failure in patients with type 2 diabetes newly treated with DPP-4 inhibitors or other oral glucose-lowering medications: a retrospective registry study on 127,555 patients from the Nationwide OsMed Health-DB Database. Eur. Heart J. 2015; 36:2454-2462. doi:10.1093/eurheartj/ehv301. [PubMed: 26112890]

Farouque HMO, Meredith IT. Effects of inhibition of ATP-sensitive potassium channels on metabolic vasodilation in the human forearm. Clin. Sci. 2003; 104:39-46. doi:10.1042/. [PubMed: 12519086]

Ferreira LF, Hageman KS, Hahn SA, Williams J, Padilla DJ, Poole DC, Musch TI. Muscle microvascular oxygenation in chronic heart failure: role of nitric oxide availability. Acta Physiol. 2006; 188:3-13. doi:10.1111/j.1748-1716.2006.01598.x.

Ferreira LF, Poole DC, Barstow TJ. Muscle blood flow- $\mathrm{O}_{2}$ uptake interaction and their relation to onexercise dynamics of $\mathrm{O}_{2}$ exchange. Respir. Physiol. Neurobiol. 2005; 147:91-103. doi:10.1016/ j.resp.2005.02.002. [PubMed: 15848127]

Fishbein MC, Maclean D, Maroko PR. Experimental myocardial infarction in the rat: qualitative and quantitative changes during pathologic evolution. Am. J. Pathol. 1978; 90:57-70. [PubMed: 619696]

Flagg TP, Enkvetchakul D, Koster JC, Nichols CG. Muscle KATP channels: recent insights to energy sensing and myoprotection. Physiol. Rev. 2010; 90:799-829. doi:10.1152/physrev.00027.2009. [PubMed: 20664073]

Hepple RT, Liu PP, Plyley MJ, Goodman JM. Oxygen uptake kinetics during exercise in chronic heart failure: influence of peripheral vascular reserve. Clin. Sci. 1999; 97:569-577. [PubMed: 10545307]

Herspring KF, Ferreira LF, Copp SW, Snyder BS, Poole DC, Musch TI. Effects of antioxidants on contracting spinotrapezius muscle microvascular oxygenation and blood flow in aged rats. J. Appl. Physiol. 2008; 105:1889-1896. doi:10.1152/japplphysiol.90642.2008. [PubMed: 18845782]

Hirai DM, Copp SW, Ferguson SK, Holdsworth CT, Musch TI, Poole DC. The NO donor sodium nitroprusside: evaluation of skeletal muscle vascular and metabolic dysfunction. Microvasc. Res. 2013; 85:104-111. doi:10.1016/j.mvr.2012.11.006. [PubMed: 23174313]

Hirai DM, Copp SW, Holdsworth CT, Ferguson SK, McCullough DJ, Behnke BJ, Musch TI, Poole DC. Skeletal muscle microvascular oxygenation dynamics in heart failure: exercise training and nitric oxide-mediated function. Am. J. Physiol. Heart Circ. Physiol. 2014; 306:H690-698. doi: 10.1152/ajpheart.00901.2013. [PubMed: 24414070]

Hirai DM, Musch TI, Poole DC. Exercise training in chronic heart failure: improving skeletal muscle $\mathrm{O}_{2}$ transport and utilization. Am. J. Physiol. Heart Circ. Physiol. 2015; 309:H1419-1439. doi: 10.1152/ajpheart.00469.2015. [PubMed: 26320036] 
Hogan MC, Arthur PG, Bebout DE, Hochachka PW, Wagner PD. Role of $\mathrm{O}_{2}$ in regulating tissue respiration in dog muscle working in situ. J. Appl. Physiol. 1992; 73:728-736. [PubMed: 1400003]

Holdsworth CT, Copp SW, Ferguson SK, Sims GE, Poole DC, Musch TI. Acute inhibition of ATPsensitive $\mathrm{K}+$ channels impairs skeletal muscle vascular control in rats during treadmill exercise. Am. J. Physiol. Heart Circ. Physiol. 2015; 308:H1434-1442. doi:10.1152/ajpheart.00772.2014. [PubMed: 25820394]

Holdsworth CT, Ferguson SK, Poole DC, Musch TI. Modulation of rat skeletal muscle microvascular $\mathrm{O}_{2}$ pressure via KATP channel inhibition following the onset of contractions. Respir. Physiol. Neurobiol. 2016; 222:48-54. doi:10.1016/j.resp.2015.11.012. [PubMed: 26592147]

Jackson WF. Hypoxia does not activate ATP-sensitive K+ channels in arteriolar muscle cells. Microcirc. N. Y. N 1994. 2000; 7:137-145.

Kawano T, Zoga V, Kimura M, Liang M-Y, Wu H-E, Gemes G, McCallum JB, Kwok W-M, Hogan $\mathrm{QH}$, Sarantopoulos CD. Nitric oxide activates ATP-sensitive potassium channels in mammalian sensory neurons: action by direct S-nitrosylation. Mol. Pain. 2009; 5:12. doi: 10.1186/1744-8069-5-12. [PubMed: 19284878]

Keller DM, Ogoh S, Greene S, Olivencia-Yurvati A, Raven PB. Inhibition of KATP channel activity augments baroreflex-mediated vasoconstriction in exercising human skeletal muscle. J. Physiol. 2004; 561:273-282. doi:10.1113/jphysiol.2004.071993. [PubMed: 15345750]

Kubo M, Nakaya Y, Matsuoka S, Saito K, Kuroda Y. Atrial natriuretic factor and isosorbide dinitrate modulate the gating of ATP-sensitive $\mathrm{K}+$ channels in cultured vascular smooth muscle cells. Circ. Res. 1994; 74:471-476. [PubMed: 8118955]

Larsen JJ, Dela F, Madsbad S, Vibe-Petersen J, Galbo H. Interaction of sulfonylureas and exercise on glucose homeostasis in type 2 diabetic patients. Diabetes Care. 1999; 22:1647-1654. [PubMed: 10526729]

Maier W, Cosentino F, Lütolf RB, Fleisch M, Seiler C, Hess OM, Meier B, Lüscher TF. Tetrahydrobiopterin improves endothelial function in patients with coronary artery disease. J. Cardiovasc. Pharmacol. 2000; 35:173-178. [PubMed: 10672847]

Miyazaki A, Adachi H, Oshima S, Taniguchi K, Hasegawa A, Kurabayashi M. Blood flow redistribution during exercise contributes to exercise tolerance in patients with chronic heart failure. Circ. J. 2007; 71:465-470. [PubMed: 17384444]

Montoya-Pérez R, Saavedra-Molina A, Trujillo X, Huerta M, Andrade F, Sánchez-Pastor E, Ortiz M. Inhibition of oxygen consumption in skeletal muscle-derived mitochondria by pinacidil, diazoxide, and glibenclamide, but not by 5-hydroxydecanoate. J. Bioenerg. Biomembr. 2010; 42:21-27. doi: 10.1007/s10863-009-9265-z. [PubMed: 20066482]

Morgan CL, Mukherjee J, Jenkins-Jones S, Holden SE, Currie CJ. Association between first-line monotherapy with sulphonylurea versus metformin and risk of all-cause mortality and cardiovascular events: a retrospective, observational study. Diabetes Obes. Metab. 2014; 16:957962. doi:10.1111/dom.12302. [PubMed: 24720708]

Murphy ME, Brayden JE. Nitric oxide hyperpolarizes rabbit mesenteric arteries via ATP-sensitive potassium channels. J. Physiol. 1995; 486:47-58. Pt 1. [PubMed: 7562643]

Musch TI, Moore RL, Riedy M, Burke P, Zelis R, Leo ME, Bruno A, Bradford GE. Glycogen concentrations and endurance capacity of rats with chronic heart failure. J. Appl. Physiol. 1988; 64:1153-1159. [PubMed: 3366736]

Musch TI, Terrell JA. Skeletal muscle blood flow abnormalities in rats with a chronic myocardial infarction: rest and exercise. Am. J. Physiol. 1992; 262:H411-419. [PubMed: 1539701]

Nakai T, Ichihara K. Effects of diazoxide on norepinephrine-induced vasocontraction and ischemic myocardium in rats. Biol. Pharm. Bull. 1994; 17:1341-1344. [PubMed: 7874055]

Nichols CG, Ripoll C, Lederer WJ. ATP-sensitive potassium channel modulation of the guinea pig ventricular action potential and contraction. Circ. Res. 1991; 68:280-287. [PubMed: 1984868]

Noma A. ATP-regulated K+ channels in cardiac muscle. Nature. 1983; 305:147-148. [PubMed: 6310409]

Respir Physiol Neurobiol. Author manuscript; available in PMC 2018 April 01. 
O’Connor E, Green S, Kiely C, O’Shea D, Egaña M. Differential effects of age and type 2 diabetes on dynamic vs. peak response of pulmonary oxygen uptake during exercise. J. Appl. Physiol. 2015; 118:1031-1039. doi:10.1152/japplphysiol.01040.2014. [PubMed: 25701005]

Padilla DJ, McDonough P, Behnke BJ, Kano Y, Hageman KS, Musch TI, Poole DC. Effects of Type II diabetes on muscle microvascular oxygen pressures. Respir. Physiol. Neurobiol. 2007; 156:187195. doi:10.1016/j.resp.2006.08.008. [PubMed: 17015044]

Piepoli MF, Guazzi M, Boriani G, Cicoira M, Corrà U, Dalla Libera L, Emdin M, Mele D, Passino C, Vescovo G, Vigorito C, Villani G, Agostoni P, Working Group "Exercise Physiology, Sport Cardiology and Cardiac Rehabilitation", Italian Society of Cardiology. Exercise intolerance in chronic heart failure: mechanisms and therapies. Part II. Eur. J. Cardiovasc. Prev. Rehabil. 2010a; 17:643-648. doi:10.1097/HJR.0b013e32833f3aa5. [PubMed: 21217245]

Piepoli MF, Guazzi M, Boriani G, Cicoira M, Corrà U, Dalla Libera L, Emdin M, Mele D, Passino C, Vescovo G, Vigorito C, Villani GQ, Agostoni P, Working Group "Exercise Physiology, Sport Cardiology and Cardiac Rehabilitation", Italian Society of Cardiology. Exercise intolerance in chronic heart failure: mechanisms and therapies. Part I. Eur. J. Cardiovasc. Prev. Rehabil. 2010b; 17:637-642. [PubMed: 21268774]

Poole DC, Behnke BJ, McDonough P, McAllister RM, Wilson DF. Measurement of muscle microvascular oxygen pressures: compartmentalization of phosphorescent probe. Microcirculation. 2004; 11:317-326. doi:10.1080/10739680490437487. [PubMed: 15280071]

Poole DC, Hirai DM, Copp SW, Musch TI. Muscle oxygen transport and utilization in heart failure: implications for exercise (in)tolerance. Am. J. Physiol. Heart Circ. Physiol. 2012; 302:H10501063. doi:10.1152/ajpheart.00943.2011. [PubMed: 22101528]

Regensteiner JG, Bauer TA, Reusch JE, Brandenburg SL, Sippel JM, Vogelsong AM, Smith S, Wolfel EE, Eckel RH, Hiatt WR. Abnormal oxygen uptake kinetic responses in women with type II diabetes mellitus. J. Appl. Physiol. 1998; 85:310-317. [PubMed: 9655791]

Richardson RS, Noyszewski EA, Kendrick KF, Leigh JS, Wagner PD. Myoglobin O2 desaturation during exercise. Evidence of limited O2 transport. J. Clin. Invest. 1995; 96:1916-1926. doi: 10.1172/JCI118237. [PubMed: 7560083]

Richardson TE, Kindig CA, Musch TI, Poole DC. Effects of chronic heart failure on skeletal muscle capillary hemodynamics at rest and during contractions. J. Appl. Physiol. 2003; 95:1055-1062. doi:10.1152/japplphysiol.00308.2003. [PubMed: 12740313]

Rumsey WL, Vanderkooi JM, Wilson DF. Imaging of phosphorescence: a novel method for measuring oxygen distribution in perfused tissue. Science. 1988; 241:1649-1651. [PubMed: 3420417]

Sacre JW, Jellis CL, Haluska BA, Jenkins C, Coombes JS, Marwick TH, Keske MA. Association of Exercise Intolerance in Type 2 Diabetes With Skeletal Muscle Blood Flow Reserve. JACC Cardiovasc. Imaging. 2015; 8:913-921. doi:10.1016/j.jcmg.2014.12.033. [PubMed: 26189114]

Schrage WG, Dietz NM, Joyner MJ. Effects of combined inhibition of ATP-sensitive potassium channels, nitric oxide, and prostaglandins on hyperemia during moderate exercise. J. Appl. Physiol. 2006; 100:1506-1512. doi:10.1152/japplphysiol.01639.2005. [PubMed: 16469932]

Silva KE, Barbosa HC, Rafacho A, Bosqueiro JR, Stoppiglia LF, Carneiro EM, Borelli MI, Del Zotto $\mathrm{H}$, Gagliardino JJ, Boschero AC. INGAP-PP up-regulates the expression of genes and proteins related to $\mathrm{K}+\mathrm{ATP}$ channels and ameliorates $\mathrm{Ca} 2+$ handling in cultured adult rat islets. Regul. Pept. 2008; 148:39-45. doi:10.1016/j.regpep.2008.02.008. [PubMed: 18378016]

Simpson SH, Majumdar SR, Tsuyuki RT, Eurich DT, Johnson JA. Dose-response relation between sulfonylurea drugs and mortality in type 2 diabetes mellitus: a population-based cohort study. Can. Med. Assoc. J. 2006; 174:169-174. doi:10.1503/cmaj.050748. [PubMed: 16415461]

Sindler AL, Delp MD, Reyes R, Wu G, Muller-Delp JM. Effects of ageing and exercise training on eNOS uncoupling in skeletal muscle resistance arterioles. J. Physiol. 2009; 587:3885-3897. doi: 10.1113/jphysiol.2009.172221. [PubMed: 19528246]

Suzuki M, Sasaki N, Miki T, Sakamoto N, Ohmoto-Sekine Y, Tamagawa M, Seino S, Marbán E, Nakaya H. Role of sarcolemmal K(ATP) channels in cardioprotection against ischemia/reperfusion injury in mice. J. Clin. Invest. 2002; 109:509-516. doi:10.1172/JCI14270. [PubMed: 11854323] 
Tateishi J, Faber JE. ATP-sensitive K+ channels mediate alpha 2D-adrenergic receptor contraction of arteriolar smooth muscle and reversal of contraction by hypoxia. Circ. Res. 1995; 76:53-63. [PubMed: 8001278]

Thomas GD, Hansen J, Victor RG. ATP-sensitive potassium channels mediate contraction-induced attenuation of sympathetic vasoconstriction in rat skeletal muscle. J. Clin. Invest. 1997; 99:26022609. doi:10.1172/JCI119448. [PubMed: 9169489]

Vanelli G, Chang HY, Gatensby AG, Hussain SN. Contribution of potassium channels to active hyperemia of the canine diaphragm. J. Appl. Physiol. 1994; 76:1098-1105. [PubMed: 7516322]

Wang H-J, Li Y-L, Gao L, Zucker IH, Wang W. Alteration in skeletal muscle afferents in rats with chronic heart failure. J. Physiol. 2010; 588:5033-5047. doi:10.1113/jphysiol.2010.199562. [PubMed: 21041525]

Wheaton WW, Chandel NS. Hypoxia. 2. Hypoxia regulates cellular metabolism. Am. J. Physiol. Cell Physiol. 2011; 300:C385-393. doi:10.1152/ajpcell.00485.2010. [PubMed: 21123733]

Wilson DF, Erecińska M, Drown C, Silver IA. Effect of oxygen tension on cellular energetics. Am. J. Physiol. 1977; 233:C135-140. [PubMed: 200145]

Yoshida T, Inoue R, Morii T, Takahashi N, Yamamoto S, Hara Y, Tominaga M, Shimizu S, Sato Y, Mori Y. Nitric oxide activates TRP channels by cysteine S-nitrosylation. Nat. Chem. Biol. 2006; 2:596-607. doi:10.1038/nchembio821. [PubMed: 16998480] 


\section{Highlights}

- Chronic heart failure impairs skeletal muscle microvascular oxygenation $\left(\mathrm{PO}_{2} \mathrm{mv}\right)$ and exercise tolerance.

- Vascular ATP-sensitive $\mathrm{K}+\left(\mathrm{K}_{\mathrm{ATP}}\right)$ channels are important modulators of muscle $\mathrm{PO}_{2} \mathrm{mv}$ during contractions in health.

- $\quad$ Herein we demonstrate that preserved $\mathrm{K}_{\mathrm{ATP}}$ channel function helps preserve $\mathrm{PO}_{2} \mathrm{mv}$ during muscle contractions in chronic heart failure. 

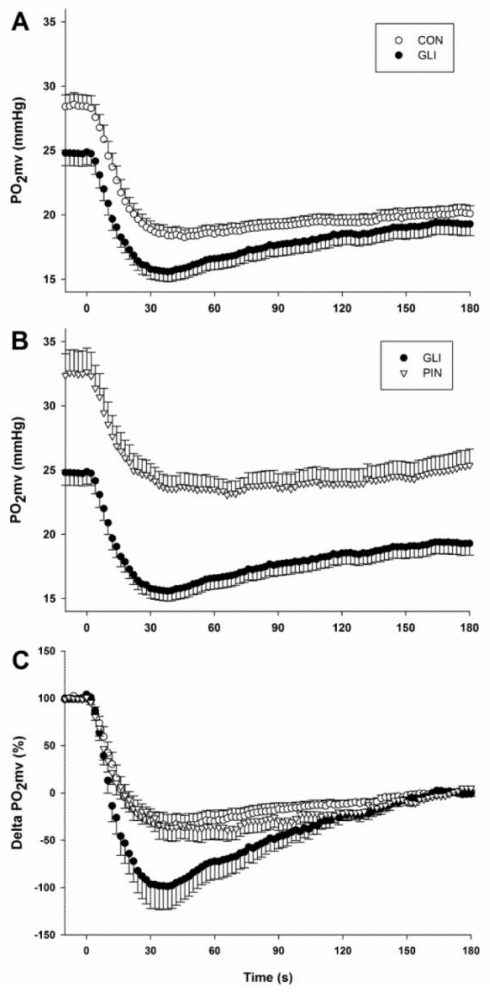

Figure 1.

Mean absolute spinotrapezius muscle $\mathrm{PO}_{2} \mathrm{mv}$ profiles for (A) control and GLI and (B) GLI and PIN in CHF rats. (C) Mean relative spinotrapezius $\mathrm{PO}_{2} \mathrm{mv}$ profiles for control, GLI and PIN in CHF rats. Contractions began at time zero. Notice the divergence of the GLI profile resulting in a marked undershoot of the steady-state $\mathrm{PO}_{2} \mathrm{mv}$. 


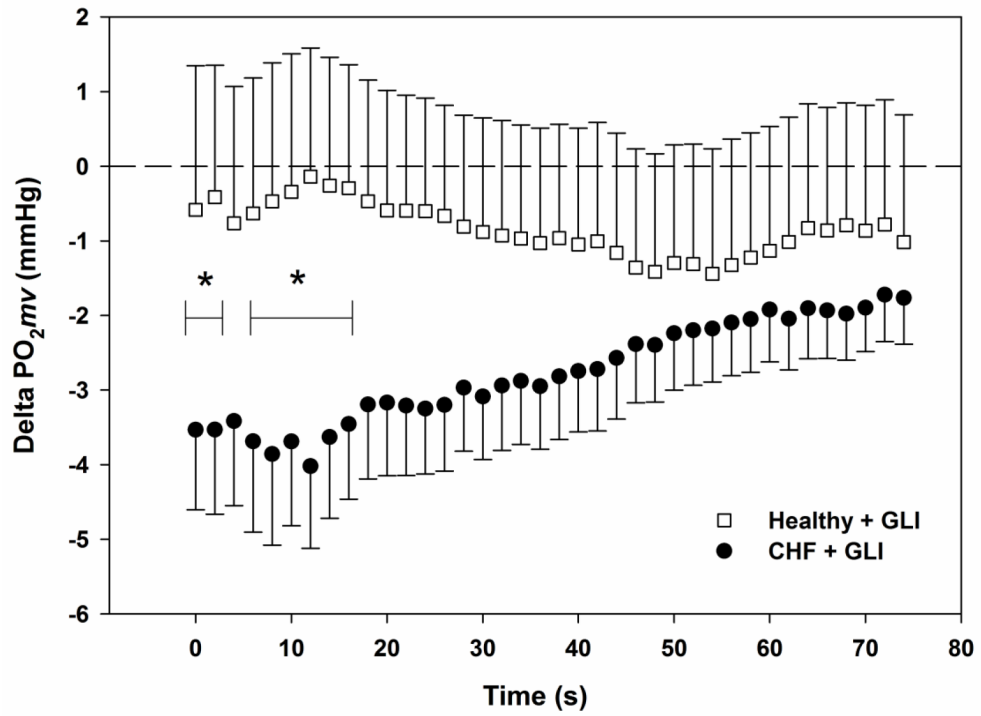

Figure 2.

Magnitude of change in spinotrapezius muscle $\mathrm{PO}_{2} \mathrm{mv}$ with GLI during the early transient from rest to contractions in healthy (data from Holdsworth et al., 2016) versus the present investigation with $\mathrm{CHF}$ rats. Contractions began at time zero. GLI superfusion of the spinotrapezius muscle was utilized herein to minimize potential alterations in MAP and HR (primarily due to reduced conductance in the renal and splanchnic vascular beds) (Duncker et al., 2001; Holdsworth et al., 2015) observed previously with intra-arterial drug administration in healthy rats (Holdsworth et al., 2016). Note the different effects of GLI on muscle $\mathrm{PO}_{2} \mathrm{mv}$ in $\mathrm{CHF}$ compared to healthy rats, indicating a greater reliance of $\mathrm{K}_{\text {ATP }}$ channel function on $\mathrm{O}_{2}$ delivery-utilization matching in this disease. See text for further details. $* p<0.05$ vs. healthy. 


\section{Table 1}

Morphological and hemodynamic characteristics of CHF rats

\begin{tabular}{|l|c|c|}
\hline & Mean \pm SEM & Range \\
\hline LVEDP, $\mathbf{~ m m H g}$ & $18 \pm 1$ & $10-27$ \\
\hline LV dp/dt, $\mathbf{~ m m H g / s ~}$ & $6270 \pm 239$ & $4900-8800$ \\
\hline LV/body mass, $\mathbf{~ m g / g}$ & $1.91 \pm 0.03$ & $1.73-2.07$ \\
\hline RV/body mass, $\mathbf{~ m g / g}$ & $0.59 \pm 0.02$ & $0.51-0.78$ \\
\hline Lung/body mass, $\mathbf{~ m g / g}$ & $3.56 \pm 0.16$ & $2.78-5.29$ \\
\hline Infarct size, \% & $30 \pm 1$ & $18-42$ \\
\hline
\end{tabular}

Data are mean \pm SEM. LVEDP, left ventricular end diastolic pressure; $L V$ dp/dt, left ventricular dpressure/dtime RV, right ventricle; LV, left ventricle. $n=16$. 


\section{Table 2}

Spinotrapezius $\mathrm{PO}_{2} \mathrm{mv}$ parameters at rest and following the onset of contractions under control, GLI and PIN conditions

\begin{tabular}{|l|c|c|c|}
\hline & Control & GLI & PIN \\
\hline $\mathbf{P O}_{2} \mathbf{m v}_{(\mathbf{B L})}, \mathbf{m m H g}$ & $28.3 \pm 0.9$ & $24.8 \pm 1.0^{*}$ & $32.5 \pm 2.0^{\dagger}$ \\
\hline $\mathbf{\Delta}_{\mathbf{1}} \mathbf{P O}_{\mathbf{2}} \mathbf{m v}, \mathbf{m m H g}$ & $11.0 \pm 0.7$ & $9.7 \pm 0.6$ & $9.7 \pm 1.2$ \\
\hline $\mathbf{\Delta}_{\mathbf{2}} \mathbf{P O}_{2} \mathbf{m v}, \mathbf{m m H g}$ & $3.3 \pm 0.2$ & $4.3 \pm 0.4^{*}$ & $2.4 \pm 0.4^{\dagger}$ \\
\hline $\mathbf{P O}_{2} \mathbf{m v}_{(\mathbf{S S})}, \mathbf{m m H g}$ & $19.6 \pm 0.6$ & $19.1 \pm 0.9$ & $23.8 \pm 1.4^{\dagger}$ \\
\hline $\mathbf{T D}_{\mathbf{1}}, \mathbf{s}$ & $5.5 \pm 0.9$ & $4.7 \pm 0.6$ & $3.0 \pm 0.7$ \\
\hline $\mathbf{T D}_{\mathbf{2}}, \mathbf{s}$ & $39.0 \pm 6.9$ & $36.8 \pm 5.2$ & $57.0 \pm 12.7$ \\
\hline $\mathbf{\tau}_{\mathbf{1}}, \mathbf{s}$ & $10.6 \pm 0.7$ & $10.3 \pm 1.0$ & $16.8 \pm 3.6$ \\
\hline $\mathbf{\tau}_{\mathbf{2}}, \mathbf{s}$ & $33.6 \pm 4.6$ & $47.1 \pm 5.4$ & $32.5 \pm 7.2$ \\
\hline $\mathbf{M R T}_{\mathbf{1}}, \mathbf{s}$ & $16.2 \pm 1.1$ & $15.0 \pm 1.0$ & $19.8 \pm 3.3$ \\
\hline $\mathbf{M R T}_{\mathbf{2}}, \mathbf{s}$ & $72.6 \pm 7.9$ & $83.9 \pm 6.3$ & $89.5 \pm 12.2$ \\
\hline $\mathbf{M R T}_{\text {Total }}, \mathbf{s}$ & $66.1 \pm 10.2$ & $93.6 \pm 7.8^{*}$ & $57.1 \pm 14.1^{\dagger}$ \\
\hline
\end{tabular}

Values are mean \pm SE. $\mathrm{PO}_{2} \mathrm{mv}(\mathrm{BL})$, resting $\mathrm{PO}_{2} \mathrm{mv} ; \Delta_{1} \mathrm{PO} 2 \mathrm{mv}$, amplitude of the first component; $\Delta_{2} \mathrm{PO}_{2} \mathrm{mv}$, amplitude of the second component; $\mathrm{PO}_{2} \mathrm{mv}(\mathrm{SS})$, contracting steady-state $\mathrm{PO}_{2} \mathrm{mv}$; $\mathrm{TD}_{1}$, time delay of the first component; $\mathrm{TD}_{2}$, time delay of the second component; $\tau$, time constant of the first component; $\tau_{2}$, time constant of the second component; MRT 1 , mean response time of the first component; MRT2, mean response time of the second component; MRTTotal, sum of the first and second component mean response times. The two-component model was used to describe the $\mathrm{PO}_{2}$ mv kinetics in the following conditions: CON (11/16); GLI (15/16); PIN (5/12).

*

$p<0.05$ vs. control.

${ }_{p}^{\dagger}<0.05$ vs. GLI.

를 